Nicholas. Surgical abortion at twenty weeks: is morality determined solely by the outcome? Fournal of medical ethics 1989; 15:82-85.

(2) Rachels J. Active and passive euthanasia. New England Fournal of medicine 1975; 292:78-80.

(3) Glover J. Causing death and saving lives. Harmondsworth: Penguin, 1977: 92-116.

J G THORNTON Lecturer in Obstetrics and Gynaecology University of Wales College of Medicine Heath Park Cardiff CF 4 4XN

\section{Response on late surgical abortion}

SIR

Thornton's repudiation of our agument seems to go something like this. We were wrong to claim that something can be morally important purely because of its symbolic effects - its effects upon our emotions. He would argue that the moral force of a symbolically unattractive action, is the result of a long-term consequence of that action (for example brutalising people). We disagree. The argument that actions are judged in terms of their outcomes, is utiltarian. Thornton wants to say that utilitarian arguments must also take into account indirect and very longterm effects, including those resulting from adverse effects on human psychology. Our argument is based on emotional considerations. In other words, we are concerned to include the symbolism of certain acts in ethical debate. We deliberately avoided using the words utilitarian and deontological, because if utilitarian considerations include emotional and symbolic effects and if they also include the very longterm outcomes of actions, then the distinction between the two becomes difficult to define. In this sense, we share ground with Thornton - we are happy to see the adverse symbolic and emotional effects of manual destruction of the fetus as an effect of the act of 'surgical abortion'. We think the symbolism of acts is important. That is why we think that sniping is a more serious violation than bombardment by cannon, all other things being equal, because of the emotional connotations of seeing the person who is about to be destroyed.
There is another serious point in which Thornton misunderstands us. We do not argue that late surgical termination is morally wrong because of the violation of human sensitivities involved. We merely said that this violation of human sensitivities has moral force and should be taken into the equation. Thus we do not say that sniping is never justified (although it happens to be our view that this is only justified by the most extreme provocation). Similarly, to take up Thornton's argument about post mortem examinations; we do think that the violation in post mortem is morally relevant, purely for its symbolic (emotional effects). This does not mean that post mortem is wrong. In this case other considerations (finding the murderer, auditing medical diagnosis) have greater force. Similarly, it is morally correct to wring the neck of a mortally injured bird, because this again is the lesser of two evils, if the bird is suffering and no other means are available to expedite its demise. We would not, however, wring the neck of the Christmas goose. Our argument is that in the case of late termination of pregnancy there is no clear evidence that surgical termination is psychologically or medically preferable, and that human sensitivities arising from the physical violation involved can legitimately be taken into account in decision-making.

\section{Moral force}

Finally, we do not believe that doctors are brutalised by carrying out physical destructive procedures, such as post mortems and terminations of pregnancy - if anything the effects are the opposite to this, provided that the procedures are morally justified. We think that the emotional impact of actions per se are morally important, quite apart from any knock-on effect of symbolically undesirable procedures. We think these factors have moral force, but this moral force is not always overriding.

Lethal intravascular injection srikes us as a sensible idea and we would not oppose a doctor doing late surgical termination if he/she believed this was safer or psychologically preferable to medical methods.

RICHARD J LILFORD MRCP, PhD, MRCOG Professor of Obstetrics and Gynaecology The University of Leeds St fames's University Hospital Leeds LS9 $7 T F$

\section{Ethical obligation arising from routine screening}

SIR

I wonder whether it is appropriate to ask for your help and that of your readers with a practical problem which a literature search has not cast any light on?

As a district we are evaluating our cervical smear service, and one of our consultant pathologists recently raised the problem of women who have attended for initial screening, but then fail to re-present to their GP when requested to do so by him or her as the laboratory has informed the doctor of an abnormality, because they have moved house but not left a full forwarding address.

Cambridgeshire FPC will check and forward the result to the new GP if someone has re-registered in the county. It becomes problematical when people move further afield, and there are a number of situations which we have already experienced which cause us concern.

The result can be included in the brown envelope if its arrival has been the stimulus which has indicated that the woman is effectively no longer a patient of that practice, but may then wait unheeded for months at the NHS Central Register before the woman reregisters and thus causes her notes to be forwarded to her new GP. She may not get round to re-registering until she develops pelvic symptoms!

If the brown envelope has gone, and the woman did not leave enough of a forwarding address with her old GP to indicate which will be her new FPC, to what extent are we morally obliged to turn detective? Is the moral imperative to inform her of her need for treatment stronger than her right to confidentiality if it proves difficult to persuade remaining relatives or friends to supply her new address? If she has gone abroad, then there is no hope that the NHS Central Register will eventually be able to find her, so we must rely on social contacts. Oddly, this seems even to apply to servicewomen, and the families of servicemen, who have been posted abroad as certainly the RAF will not routinely forward NHS results.

It is our feeling that the fact that these abnormalities have been found as a result of a health-service-instigated investigation (the call or recall of a routine screening service) rather than 
during a patient-initiated episode, places us under an even greater than usual obligation to ensure that the patient has access to the most appropriate care.

These must be problems which are being considered in other districts, and the Cervical Cytology Steering Committee here in Huntingdon would be most interested and grateful to hear what expert opinion is on them.

VIRGINIA WARREN MA MD Registrar in Public Health Medicine Huntingdon Health Authority District Headquarters Primrose Lane Huntingdon Cambs PE18 6SE

\section{What doctors should call their patients}

SIR

Lavin (1) argues that unreciprocated informality towards patients inhibits their ability to make adult choices. He was referring to the patient-doctor relationship, but the remark is equally applicable to the relationship between patients and other members of staff.
In some British hospitals health care professionals present themselves with titles and surnames, for example, 'Nurse Brown', while addressing their patients informally as 'Jill' or 'John'. When challenged, the staff will often claim that patients like to be addressed in this manner. Perhaps some do; it is also possible that some pretend to like it since, in their vulnerable state as patients, they will tend to present a view in line with current practice.

If we look for a parallel of unreciprocated first-naming, we can find it in the school-room where John calls his teacher 'Miss' and she calls him 'John'. The unequal relationship is explicit as it is between employer and employee.

Situations involving adult strangers of potentially equal standing however, require modes of address that are reciprocal as witnessed between lawyer and client. There seems no reason why the medical scene should warrant a different approach in this respect.

Since the school-room example is concerned with establishing authority, we are left wondering whether the same principle is being applied in the hospital setting, ie, that unreciprocated firstnaming of patients is a conscious or unconscious attempt to place them in a subordinate role.

There seems to be no case for unreciprocated first-naming. The more fashionable reciprocated first-naming is however, an alternative of questionable value: an elderly person being attended by a young nurse may be surprised to find him or herself in a first-naming situation since in no other social setting would immediate familiarity be likely to occur. Far from making the patient feel welcome, this approach might be inclined to make the patient bristle. Since many people enter hospital with an already high blood pressure, anything which tends to raise it further would seem to be counter-productive.

Come to think of it, what was wrong with reciprocated formality?

\section{Reference}

(1) Lavin M. What doctors should call their patients. Fournal of medical ethics 1988; 14:129-131.

ROSEMARY PAYNE, BSC MCSP State Registered Physiotherapist 1 St Michael's Road Llandaff 